\title{
A Note on Horizontal Diffusion from an Instantaneous Source in a Nonuniform Flow*
}

\begin{abstract}
Akira OKUBO**
Abstract : Horizontal diffusion from an instantaneous source in a nonuniform flow is studied theoretically by use of a transport equation. The treatment is limited to a field of mean velocity having components that are linear functions of the coordinates relative to the center of mass of the patch. Thus, this model may represent the turbulent diffusion from an instantaneous source in a turbulent field in which the characteristic length of large-scale eddies is much larger than the size of diffusing patch. The total dispersion of the patch is determined by the combined effect of diffusion due to the small eddies and of convection due to the larger eddies. The model may interpret partially the observed elongation of diffusing patches in the sea and the orientation of the elongated patches with respect to the mean flow, i.e. the flow in the largescale eddies.
\end{abstract}

\section{Introduction}

Various theoretical models of horizontal diffusion from an instantaneous source in the sea have been proposed in which the coefficient of diffusion is taken as a function of either the distance from the center of a diffusing patch, the time of diffusion or both (see papers reviewed by OKuBO, 1962, and by BOWDEN, 1964). These treatments are concerned primarily with the diffusion due to the randam movements of water. Thus, no allowance is made explicitly for factors such as shear in the mean velocity. Furthermore, these theories are not concerned with the shape of the diffusing patch, i.e., the elongation phenomenon.

Recently BOWDEN (1965) has investigated mixing due to a shearing current, where the vertical gradient of velocity combined with vertical turbulent mixing leads to an effective diffusion in the horizontal direction (the "shear

* Received Dec. 20, 1965

Contribution No. 88 of Chesapeake Bay Institute and the Department of Oceanography. This work was supported by the U.S. Atomic Energy Commission under contract AT(30-1)-3109 and by the Office of Naval Research, contract Nonr 4010 (11).

** Chesapeake Bay Institute, The Johns Hopkins University, Baltimore, Maryland effect") and hence, gives rise to the elongation of a diffusing patch predominantly in the longitudinal direction. In general, the effective coefficient is inversely proportional to the coefficient of vertical eddy diffusion in a vertically bound sea. Diffusion by this process is likely to be most effective in shallow waters, e.g., estuaries (HARLEMAN, 1964), and on a smallscale phenomenon, say for 100 meters in diameter.

BOWDEN (1965) also suggests that at greater distance from the coast and for larger-scale phenomena the influence of larger horizontal eddies will probably predominate in the horizontal diffusion. The present author will examine analytically the effect of inhomogeneity in the mean velocity associated with the largescale horizontal eddies on horizontal diffusion of substance released from an instantaneous source.

\section{Basic equation of diffusion and its solution}

For simplicity consider two-dimensional horizontal diffusion due to uniform gradients of the mean velocity in an unbounded sea. Generalization to three-dimensional case would be a matter of adding the third dimension unless the concentration distribution of substance becomes modified seriously by any horizontal boundary. After the presence of the boundaries makes 
itself felt, an effective longitudinal dispersion is produced by the combination of a vertical gradient of the mean velocity with vertical eddy diffusion (BOwDEN, 1965), and, then, the depth-mean concentration of substance may be investigated by a quasi-two-dimensional theory, using the effective value of the longitudinal coefficient of diffusion added linearly to the genuine value of the horizontal coefficient. In other words, the present treatment may provide a fundamental knowledge of horizontal diffusion in the sea due to a nonuniform current.

To construct a working model of diffusion, we propose a hypothetical spectrum of turbulence which consists of two major parts: the largescale eddies and the small-scale eddies. The two eddies are sufficiently separated in scale so that the scale of diffusion lies somewhere between the two scales of the eddies. As a consequence of this hypothesis, the following are deduced.

a) The large-scale eddies provide the nonuniformity in the mean velocity. The inhomgeneity appears primarily as steady uniform velocity-gradient in the horizontal direction. Hence, the mean velocites $U$ and $V$ are expressed as

$$
\begin{aligned}
& U \simeq U_{0}+\left(\frac{\partial U}{\partial x}\right)_{0} x+\left(\frac{\partial U}{\partial y}\right)_{0} y, \\
& V \simeq \quad\left(\frac{\partial V}{\partial x}\right)_{0} x+\left(\frac{\partial V}{\partial y}\right)_{0} y,
\end{aligned}
$$

where $\left(\frac{\partial U}{\partial x}\right)_{0}$ etc, are constant, $U_{0}$ the mean flow originated from the largest eddies. The coordinate system is taken in such a war that the $x$-axis is directed in the mean flow, $U_{0}$, and the $y$-axis lateral.

Defining

$$
\begin{aligned}
& \alpha \equiv\left(\frac{\partial U}{\partial x}\right)_{0}, \quad \beta \equiv\left(\frac{\partial V}{\partial y}\right)_{0}: \\
& h \equiv \frac{1}{2}\left\{\left(\frac{\partial V}{\partial x}\right)_{0}+\left(\frac{\partial U}{\partial y}\right)_{0}\right\}: \\
& \text { shearing deformation, } \\
& \eta \equiv \frac{1}{2}\left\{\left(\frac{\partial V}{\partial x}\right)_{0}-\left(\frac{\partial U}{\partial y}\right)_{0}\right\}: \text { vorticity, }
\end{aligned}
$$

and assuming the horizontal nondivergence in the mean velocity field $(\beta=-\alpha)$, we can write the mean velocities $U$ and $V$ as

$$
\begin{aligned}
& U=U_{0}+\alpha x+(h-\eta) y, \\
& V=(h+\eta) x-\alpha y .
\end{aligned}
$$

b) The small-scale eddies are responsible primarily for internal mixing. Since the characteristic time and length associated with the small-scale eddies are very small in comparison with those of observation, we may use the mixing-length theory for the diffusion due to these small eddies. Thus, we may introduce the horizontal eddy diffusivity, $A$, which is asssumed to be constant with respect to time and space.

We shall now write down the basic equation of diffusion in our model;

$$
\begin{aligned}
\frac{\partial S}{\partial t} & +\left\{U_{0}+\alpha x+(h-\eta)\right\} \frac{\partial S}{\partial x} \\
& +\{(h+\eta) x-\alpha y\} \frac{\partial S}{\partial y}=A\left(\frac{\partial^{2} S}{\partial x^{2}}+\frac{\partial^{2} S}{\partial y^{2}}\right),
\end{aligned}
$$

where $S(t, x, y)$ represents the concentration of substance.

Since the velocity $U_{0}$ has nothing to do with the relative diffusion of the substance, we can eliminate $U_{0}$ from (3) by taking a coordinate system moving with $U_{0}$. We thus have

$$
\begin{aligned}
\frac{\partial S}{\partial t} & +\{\alpha x+(h-\eta) y\} \frac{\partial S}{\partial x} \\
& +\{(h+\eta) x-\alpha y\} \frac{\partial S}{\partial y}=A\left(\frac{\partial^{2} S}{\partial x^{2}}+\frac{\partial^{2} S}{\partial y^{2}}\right),
\end{aligned}
$$

with the understanding that the coordinate system $(x, y)$ in (4) is the system moving with the patch of substance.

As an initial condition we take

$$
S(o, x, y)=Q \delta(x) \delta(y),
$$

where $Q$ is the amount of substance released per unit depth and $\delta(\nu)$ denotes a Dirac function of the variable $\nu$.

As the boundary condition we take

$$
\mathrm{S}(t, x, y) \rightarrow 0 \text { as } x^{2} \rightarrow \infty \text { or } y^{2} \rightarrow \infty .
$$

The solution of (4) subject to (5) and (6) may be obtained somewhat easily in a Lagrangian frame. For this purpose, designate the concentration in the Lagrangian frame as

$$
\Gamma(t, a, b) \equiv S[t, x(t, a, b), y(t, a, b)],
$$

where $a$ and $b$ represent the initial coordinates 
of any particle of the introduced substance, and $x(t, a, b)$ and $y(t, a, b)$ are its coordinates at $\mathrm{t}$. We regard $x$ and $y$ as functions of the indepen- dent variables $t, a$ and $b$. Equation (4) can then be transformed into the following Lagrangian diffusion equation (Corrsin, 1962).

$$
\begin{aligned}
\frac{\partial \Gamma}{\partial t}= & A\left[\frac{\partial^{2} \Gamma}{\partial a^{2}}\left\{\left(\frac{\partial x}{\partial b}\right)^{2}+\left(\frac{\partial y}{\partial b}\right)^{2}\right\}+\frac{\partial^{2} \Gamma}{\partial b^{2}}\left\{\left(\frac{\partial x}{\partial a}\right)^{2}+\left(\frac{\partial y}{\partial a}\right)^{2}\right\}-2 \frac{\partial^{2} \Gamma}{\partial a \partial b}\left\{\frac{\partial x}{\partial a} \frac{\partial x}{\partial b}+\frac{\partial y}{\partial a} \frac{\partial y}{\partial b}\right\}\right. \\
& +\frac{\partial \Gamma}{\partial a}\left\{\frac{\partial^{2} x}{\partial a \partial b} \frac{\partial x}{\partial b}+\frac{\partial^{2} y}{\partial a \partial b} \frac{\partial y}{\partial b}-\frac{\partial^{2} x}{\partial b^{2}} \frac{\partial x}{\partial a}-\frac{\partial^{2} y}{\partial b^{2}} \frac{\partial y}{\partial a}\right\} \\
& \left.+\frac{\partial \Gamma}{\partial b}\left\{\frac{\partial^{2} x}{\partial a \partial b} \frac{\partial x}{\partial a}+\frac{\partial^{2} y}{\partial a \partial b} \frac{\partial y}{\partial a}-\frac{\partial^{2} x}{\partial a^{2}} \frac{\partial x}{\partial b}-\frac{\partial^{2} y}{\partial a^{2}} \frac{\partial y}{\partial b}\right\}\right] .
\end{aligned}
$$

The initial condition is expressed also in the Lagrangian form.

$$
\Gamma(o, a, b)=Q \delta(a) \delta(b) .
$$

Comparing the Lagrangian form (8) with the Eulerian (4), one notices that the convection terms somewhat complex in the Eulerian description have vanished, and, instead, the diffusion terms appear in a complex form in the Lagragian frame. Fortunately, the complex diffusion terms are reduced to a simple form in a case of the uniform rates of strain field.

To this end, we obtain first the displacements $x$ and $y$ in terms of $t, a$, and $b$ from the relations:

$$
\begin{aligned}
& \frac{\partial x}{\partial t}=U(t, x, y)=\alpha x+(h-\eta) y, \\
& \frac{\partial y}{\partial t}=V(t, x, y)=(h+\eta) x-\alpha y .
\end{aligned}
$$

Solving (10) and (11) for $x$ and $y$ subject to the conditions that $x=a$ and $y=b$ at $t=0$, we obtain

$$
\begin{gathered}
x=\frac{1}{2 \phi}\left[\{(\phi+\alpha) a+(h-\eta) b\} e^{\phi t}\right. \\
\left.+\{(\phi-\alpha) a-(h-\eta) b\} e^{-\phi t}\right], \\
y=\frac{1}{2 \phi}\left[\frac{(\phi-\alpha)\{(\phi+\alpha) a+(h-\eta) b\}}{h-\eta} e^{\phi t}\right.
\end{gathered}
$$

$$
\begin{aligned}
\Gamma(t, a, b,)= & \frac{Q}{4 \pi A\left[\int_{0}^{t}\left(F_{1}^{2}+G_{1}^{2}\right) d t^{\prime} \int_{0}^{t}\left(F_{2}^{2}+G_{2}^{2}\right) d t^{\prime}-\left\{\int_{0}^{t}\left(F_{1} F_{2}+G_{1} G_{2}\right) d t^{\prime}\right\}^{2}\right]^{1 / 2}} \\
& \exp -\left[\frac{\left[\int_{0}^{t}\left(F_{1}^{2}+G_{1}^{2}\right) d t^{\prime} a^{2}+2 \int_{0}^{t}\left(F_{1} F_{2}+G_{1} G_{2}\right) d t^{\prime} a b+\int_{0}^{t}\left(F_{2}^{2}+G_{2}^{2}\right) d t^{\prime} b^{2}\right]}{4 A\left\{\int_{0}^{t}\left(F_{1}^{2}+G_{1}^{2}\right) d t^{\prime} \int_{0}^{t}\left(F_{2}^{2}+G_{2}^{2}\right) d t^{\prime}-\left(\int_{0}^{t}\left(F_{1} F_{2}+G_{1} G_{2}\right) d t^{\prime}\right)^{2}\right\}}\right] .
\end{aligned}
$$

We shall next transform (16) back into the Eulerian form $S(t, x, y)$. The manipulation is 
straightforward; obtain $a$ and $b$ in terms of $x, y$ and $t$ from (12) and (13) and substitute them into (16). The result then yields the solution:

$$
S(t, x, y)=\frac{Q}{4 \pi A P(t)} e^{-\frac{C_{1}(t) x^{2}+2 C_{2}(t) x y+C_{8}(t) y^{2}}{4 A P^{2}(t)}},
$$

where

$$
\begin{aligned}
P(t) & =\left\{\frac{h^{2}+\alpha^{2}}{\left(h^{2}+\alpha^{2}-\eta^{2}\right)^{2}} \sinh ^{2}\left(h^{2}+\alpha^{2}-\eta^{2}\right)^{1 / 2} t-\frac{\eta^{2}}{h^{2}+\alpha^{2}-\eta^{2}} t^{2}\right\}^{1 / 2}, \\
C_{1}(t) & =\frac{h^{2}+\alpha^{2}+h \eta}{2\left(h^{2}+\alpha^{2}-\eta^{2}\right)^{3 / 2}} \sinh 2\left(h^{2}+\alpha^{2}-\eta^{2}\right)^{1 / 2} t-\frac{h \eta+\eta^{2}}{h^{2}+\alpha^{2}-\eta^{2}} t-\frac{\alpha}{h^{2}+\alpha^{2}-\eta^{2}} \sinh ^{2}\left(h^{2}+\alpha^{2}-\eta^{2}\right)^{1 / 2} t, \\
C_{2}(t) & =\frac{\alpha \eta}{2\left(h^{2}+\alpha^{2}-\eta^{2}\right)^{3 / 2}} \sinh 2\left(h^{2}+\alpha^{2}-\eta^{2}\right)^{1 / 2} t-\frac{\alpha \eta}{h^{2}+\alpha^{2}-\eta^{2}} t+\frac{h}{h^{2}+\alpha^{2}-\eta^{2}} \sinh ^{2}\left(h^{2}+\alpha^{2}-\eta^{2}\right)^{1 / 2} t, \\
C_{3}(t) & =\frac{h^{2}+\alpha^{2}-h \eta}{2\left(h^{2}+\alpha^{2}-\eta^{2}\right)^{3 / 2}} \sinh 2\left(h^{2}+\alpha^{2}-\eta^{2}\right)^{1 / 2} t+\frac{h \eta-\eta^{2}}{h^{2}+\alpha^{2}-\eta^{2}} t+\frac{\alpha}{h^{2}+\alpha^{2}-\eta^{2}} \sinh ^{2}\left(h^{2}+\alpha^{2}-\eta^{2}\right)^{1 / 2} t .
\end{aligned}
$$

For special cases, equation (17) is reduced to forms already found.

Case i)

$$
\begin{gathered}
\alpha=h=0, \quad \eta \neq 0 \\
S=\frac{Q}{4 \pi A t} e^{-\frac{x^{2}+y^{2}}{4 A t} .} .
\end{gathered}
$$

(solid rotation)

Case ii)

$$
\begin{gathered}
h=\eta=0, \quad \alpha>0 \quad \text { (pure stretch } \\
\left.\left.-e^{-2 \alpha t}\right)\right\}^{1 / 2}
\end{gathered} e^{-\left\{\frac{x^{2}}{2 \frac{A}{\alpha}\left(e^{2 \alpha t}-2\right)}+\frac{y^{2}}{2 \frac{A}{\alpha}\left(1-e^{-2 \alpha t}\right)}\right\},}
$$

which was obtained by TOwNSEND (1951).

Case iii)

$$
\begin{gathered}
\alpha=0, \quad h=-\eta>0 \\
S=\frac{Q}{4 \pi A t\left(1+\frac{1}{12} h^{2} t^{2}\right)^{1 / 2}} e^{-\frac{x^{2}-h t x y+\left(1+\frac{1}{3} h^{2} t^{2}\right) y^{2}}{4 A t\left(1+\frac{1}{12} h^{2} t^{2}\right)}},
\end{gathered}
$$

which was first given by Novikov (1958).

\section{Discussion}

Equation (17), having a quadratic form in $x$ and $y$, states that the contours of the concentration are a set of ellipses with common principal axes, the orientation of which varies with time. Thus, the substance patch is elongated in general.

On the basis of the solution (17) we can compute certain characteristics of diffusion, such as $\theta$ (the angle of orientation of the principal axes), $\rho$ (the ratio of the minor axis to the major axis), $\sigma_{1}^{2}$ and $\sigma_{2}^{2}$ (the variances in the directions of the major and minor principal axes), $\sigma^{2} \equiv \sigma_{1} \sigma_{2}$ (the mean variance) and
$K_{a} \equiv \frac{1}{2} \frac{d \sigma^{2}}{d t}$ (the apparent coefficient of horizontal diffusion). Thus, we obtain the theoretical behavior of some characteristics of diffusion in the limiting cases of $t$.

Case $I: t$ is very small compared with the charcteristic time of the velocity inhomogeneity, $t \ll t_{c} \equiv\left[h^{2}+a^{2}-\eta^{2}\right]^{1 / 2}$.

The angle of orientation of the patch becomes

$$
\theta \rightarrow \frac{1}{2} \tan ^{-1} \frac{h}{\alpha}=\theta_{s t},
$$

where $\theta_{s t}$ denotes the angle of orientation for the major axis of the rates of strain quadric. In other words, the patch starts to diffuse most 
rapidly in the direction of the major principal axis of the rates of strain. In a uniform shear field, for example, the initial angle of orientation of patches will be 45 degrees to the direction of the mean flow.

Case II: $t$ is very large. $\left(t \gg t_{c}\right)$, but is not so large as the patch covers a scale comparable to that of the large eddies. The asymptotic behavior of the characteristics may be classified into two types depending on the sign of $h^{2}+\alpha^{2}-\eta^{2}$.

i) $h^{2}+\alpha^{2}-\eta^{2} \geqslant 0$

A very much elongated patch will appear after a long time after release. Particularly in a uniform shear, the elongation occurs almost in the direction of the mean flow. The relative predominance of the deformation field over the rotational motion in the large eddies is responsible for the eventual elongation of the patch, and at the same time, the combined effect of the nonuniform convective motion and of the small-scale diffusion accelerates, to a great extent, the rate of dispersion of substance.

ii) $h^{2}+\alpha^{2}-\eta^{2}<0$

The eventual shape of the patch is not necessarily very much elongated. The more predominant the rotational motion over the deformation in the large-scale eddies, the more concentrated will be the shape of the patch. The apparent coefficient of diffusion attains a certain limiting value. One should note, in this case, that there is a unique relation between the angle of orientation of the patch in the initial period and that in the final period of diffusion, viz., the angle between them is 45 degrees. Such a unique relation does not exist in case $i$ ).

In Fig. 1 we show schematically the temporal behavior of some characteristics in both cases. These theoretical results suggest that it might be possible from analyses of diffusion experiments to explore the characteristics of the large-scale eddies in the sea, e. g., the mean-square variations in vorticity and the mean-square rates of strains of the large-scale eddies. Apparently there are some difficulties in the comparison of the theory with observations. First of all, very little information about the large scale eddies would be obtained in experiments. Secondly, the energy spectra of the actual turbulence in
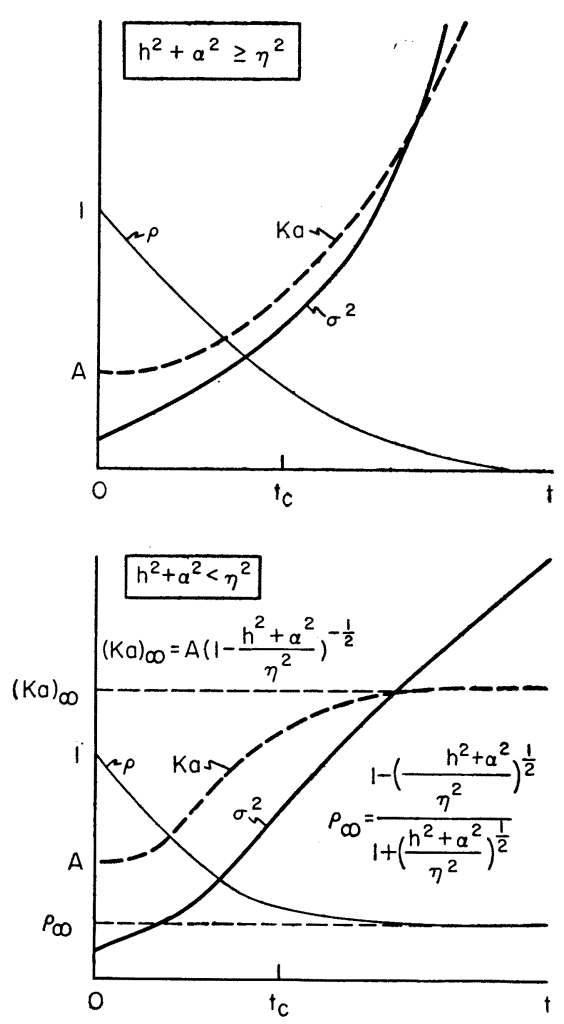

Fig. 1. Theoretical behavier of characteristics of diffusion with time. $t_{c}=\left|h^{2}+\alpha^{2}-\eta^{2}\right|^{\frac{1}{2}}$, $\sigma^{2}$ : variance, $K_{a}$ : apparent coefficient of diffusion, $\rho$ : ratio of the minor axis to the major axis.

the sea might be different far from the hypothetical spectrum taken in the present model. Nevertheless, it would be most desirable to make careful comparisons between theoretical and experimental results. It is hoped that such a comparison can be made in the future. Some tentative comparisons of the theory with dyerelease experiments were made by OKUBO (1965).

The author wishes to express his appreciation to Dr. O. M. PHILlips of the Department of Mechanics, for useful suggestions and comments, without which this note would have hardly appeared. The author is also indebted to Dr. K. F. BOWDEN, University of Liverpool and Dr. D. W. PRITCHARD, for their encouragement on this study. 


\section{References}

BOWDEN, K. E. (1964): "Turbulence" in Oceanogr. Mar. Biol. Ann. Rev., 2, 11-30.

BowDEN, K. F. (1965): Horizontal mixing in the sea due to a shearing current. Jour. Fluid Mech., 21, Part 2, 83-95.

CORRSIN, S. (1962): Theories of turbulent dispersion, in Mécanique de la turbulence, Paris, 27-52.

HARLEMAN, D. R. F. (1964): The significance of longitudinal dispersion in the analysis of pollution in estuaries. Proc. Second Int. Water Poll. Res. Conf. Tokyo. 1964.
Novikov, E. A. (1958): Concerning a turbulent diffusion in a stream with a transverse gradient of velocity. Jour. Appl. Math. and Mech., 22, 576-579 (translated from Russian).

OkUBO, A. (1962): A review of theoretical models of turbulent diffusion in the sea. Jour. Oceanogr. Soc. Japan, 20th Anniv. Vol., 286-320.

OKUBO, A. (1965): A theoretical model of diffusion of dye patches (Summary), Proc. Symp. Diffusion in Oceans and Fresh Waters held in 1964.

Townsend, A. A. (1951): The diffusion of heat spots in isotropic turbulence. Proc. Roy. Soc. London, A209, 418-430.

\section{不均一速度場における点源からの水平拡散のノート}

大 久保明

要旨 不均一な流れの中での点源からの水平拡散を輸送 方程式に基づいて考察した。とり扱いは平均速度の勾配 が一様である場合に限定された。すなわち, 平均速度は 拡散するパッチの中心に関して一次的であると仮定し た。

この模型はスケールの小さい乱れに加えるに，拡散の スケールに比へててかなり大きい乱れが存在する場合の乱 流拡散に対応している。パッチの拡散はスケールの小さ
い乱れと，スケールの大きい乱れの組合わさった効果が 現われ，スケールの大きな乱れの構造が究極的なパッチ の拡散を支配する。

この模型は海洋抎散実験で観測されている種々の事実 (たとえばパッチが細長く伸びる現象とか, パッチの主軸 の配位の時間的変動とか）を或る程度解釈するのに役立 つであろう。 